JWAM

14,1

Received 30 January 2021

Revised 8 April 2021 20 May 2021

Accepted 25 May 2021

\section{Designing playful employee experience through serious play- reflections from pre-pandemic corporate learning events in Poland}

\author{
Monika Sońta \\ Department of Management in Digital and Networked Societies, \\ Kozminski University, Warszawa, Poland
}

\begin{abstract}
Purpose - In times of organizational thirst for employee engagement and meaning through designing corporate stories, the aim of this article is to explore and identify key sources (engines) of engagement during LEGO® SERIOUS PLAY ${ }^{\circledR}$ (LSP) corporate learning pre-pandemic events of various types and size in Poland. Design/methodology/approach - This is a conceptual paper. The research was conducted using participant observation from the perspective of a certified facilitator of the method. This position ensures a prime access to the organizational events. Eight training sessions (four LSP and four non-LSP workshops) have been analysed using thematic analysis. The structure of thematic codes has been conceptualized and reflected as the EPIC framework.

Findings - The findings include (1) the importance of the experience of emerging realities as a key generator of engagement, (2) the significance of social collaboration and peer-to-peer interactions (experience of collective intelligence), (3) the observable rise in engagement and willingness to contribute when real business situations, especially labelled as "strategic issues" are discussed and (4) the role of image-capturing ("snapshot experience") in creation of an engaging learning experience.

Research limitations/implications - The limitations refer to the potential conflict of interests as the researcher is also the facilitator of the workshop. To ensure the neutral point of view of the researcher, the sessions have been recorded to enable transparency of the observation and non-biased logic of key findings. The "learning experience" research is also culture- and context-sensitive, thus it may be problematic to replicate the research procedure in different countries, however, the EPIC model can be treated as a universal framework to explore and identify the engines of engagement.

Practical implications - The concept of this paper is designed from the practical point of view. The findings are adaptable to the corporate practices aimed at empowering employees and are compatible with management models such as agile, human enablement and human-centred design in organizations.

Social implications - Serious play methods of learning and experiencing are said to be of the highest importance when finding new ways of organizational learning in the pandemic situation and work from home as a standard learning environment.

Originality/value - The contribution of this paper is visible in the conceptualization of the moments that shape an engaging experience. This is also the first academic paper presenting the perspective of a certified facilitator of LSP from Central and Eastern Europe region.
\end{abstract}

Keywords Lego serious play, Employee experience, Organizational events, Employee engagement Paper type Conceptual paper

\section{Introduction}

People intrinsically seek joy.

And joy connects people more powerfully than almost any other human experience (Liu, 2019, p. 2).

(C) Monika Sońta. Published in Journal of Work-Applied Management. Published by Emerald Publishing Limited. This article is published under the Creative Commons Attribution (CC BY 4.0) licence. Anyone may reproduce, distribute, translate and create derivative works of this article (for both commercial and non-commercial purposes), subject to full attribution to the original publication and authors. The full terms of this licence may be seen at http://creativecommons.org/licences/by/4.0/legalcode 
In times of remote work and digital employee experience (DEX), it is implored to understand the pre-pandemic sources of engaging work experiences to rewire corporate learning practices and build back better. Even before coronavirus disease 2019 (COVID)-related crises, organizations were wresting with finding ways to engage employees as the concept of play was related to various fields:

(1) as an accelerator of job satisfaction and productivity (Abramis, 1990; Inamizu and Makishima, 2018);

(2) as a support in leadership development through enablement of interpersonal interplays and interactions and embracing diversity (Kark, 2011), and

(3) as the core element that impacts culture of innovation (Schrage, 2000) through unlashing creativity and curiosity at an individual, team and organizational level (Eghenter, 2018).

In the new remote organizational context, the playful methods of learning such as LEGO ${ }^{\circledR}$ SERIOUS PLAY ${ }^{\circledR}$ (LSP) are associated with greater engagement. They are being discussed even more vividly as a promising way to cope with business ambiguity and complexity through impacting organizational positivity in general. One of the crucial dimensions is creation of higher situational awareness and better perception of psychological safety at work as LSP offers frameworks to discuss the threating emotions and encouraging selfreflexivity (Wheeler et al., 2020).

Moreover, with new normal already here, the rising notion "serious play" helps in meaning-making of the terms such as business efficiency, innovation and adaptability as it refers to learning traditional and virtual activities that enable individuals to engage in playful way, still having business intended outputs (Bonneu et al., 2017) in the centre of actions. What is even more impactful, creating the professional frameworks that enable to share experiences and emotions is crucial to employee's mental health, especially when " $\mathrm{r}$ ] eflecting critically, and sharing the outcomes of this, can be frightening and can cause feelings of vulnerability amongst those exposing their thoughts and findings" (Helyer, 2015, p. 18).

The objective of this paper is to shed exploratory light on the sources of engagement during the offline learning events to formulate directions about transferring sources of engagement to virtual corporate learning. The author bases on observations to identify the elements that build the climate of engagement during the developmental events. All the sessions have been conducted in multinational companies in Poland using solely LSP as a method.

First, the theoretical background will be briefly introduced to propose the experiences and moments of the workshops that ignited the observable engagement in the room. These based on the pre-pandemic events findings will be streamed into the EPIC(s) model and then will be translated to practical implications for managers in the digital workplaces.

\section{Theoretical underpinnings}

The area of employee engagement can be researched and observed from various points of view through the lens of theories of motivation, gamification, human resources and organization studies. With such a wide possibility for theoretical reflection, the starting point of this discussion will be a niche work of Gauntlett (2007) who situated LSP method on the map of creative qualitative research. Thus, in this paper, the author will focus on the concept of play, "playful learning activity" and social constructivism that create context for the discussion about employee experience and engagement. The theoretical discussion will try to combine communicative constitution of organization in the context of qualitative
Designing
playful
employee
experience 
JWAM

14,1 organizational research. To narrow the complexity of this multidisciplinary topic, the author will use multiple references to Gauntlett's not well-established, yet a refreshing concept on employee engagement research. To understand the term of "engaging learning experience", the author will discuss briefly Gauntlett's concept of "the Four pillars of engagement". According to this theory, the core elements of engagement are metaphors, concept of play, theory of flow and social constructivism. The abovementioned concepts will give the reader a frame to understand the notions of "Playful Activities" and "Employee Experience" in the corporate learning.

\subsection{Theorizing "playful activity"}

According to Johan Huizinga (1995) and his classic definition of "play" in "Homo ludens": "Play is a free activity standing quite consciously outside 'ordinary' life as being 'not serious,' but at the same time absorbing the player intensely and utterly" (p. 13). This definition is not accurate in the business environment due to two enforced elements:

(1) structure of the workshop-deliberate frameworks are set by the method

(2) rules that frame the social interactions during the LSP workshop.

The rules need to be added to emphasize the social character of playful experience as the whole workshop is based on socially agreed-upon regulations. In case of organizational events they play a role of social agreement before the training and are imposed by the method that demands the agreement to certain behaviours, for example "everybody builds, and everybody shares" rule. Interestingly, the concept of play itself introduces a space where the workshop participants need to accept ambiguity through the "betwixt-and-between nature of play" introduced by Huizinga (1955). Finally, with the rules of the workshop, the permission to play is given and this kind of way of learning is aligned with our biology as enjoying themselves and playing is part of human nature (Holmes and Douglas, 2012).

On one hand, the challenge with the conceptualization begins with the interpretation: Play is generally defined as an activity that participants engage in voluntarily and without coercion (Andersen, 2009, p. 77; Executive Discovery, LLC, 2002, p. 4; Huizinga, 1955, pp. 7-10). So, this interpretation: "If participants are coerced or otherwise forced into an activity, it ceases to be playful" (Hinthorne and Schneider, 2012, p. 2806) makes Huizinga's approach to "playing" inadequate to the business environment. On the other hand, play by definition requires order and flexibility (Hinthorne and Schneider, 2012, p. 2807) or is even treated as an order-creating activity. It is structured by rules or agreements among players, which may or may not be different from those that guide social interaction in ordinary life (Andersen, 2009, p. 78; Huizinga, 1955, p. 10; also see Brown, 2009). The various rhetoric of purposeful play (play as progress) and children's play as frivolity are repeated by Ashton and Giddings (2018) .

Moreover, "serious play" should lead to an identified purpose (Statler et al., 2011, p. 236) with a definition proposed by Statler (Statler et al., 2011, p. 236) that refers to a description of "situations in which people engage in playful behaviours deliberately with the intention to achieve serious, work-related objectives". That differs from "just playing" that is conducted for pure enjoyment provides the new perspective of "in-between work and joy" space. The definition of "serious play" understood as a goal oriented and concerned with outcomes as well as processes can be found in the academic paper of Andersen (2009) and Roos (2006). The constraint is related to socially constructed Paradox of Intentionality (Statler et al., 2011) as on one hand embedding serious play in learning enhances opportunities to re-frame the context of corporate conversations, and contextual setting in general and extend imagination of employees, on the other serious play disrupts patterns of behaviours and expression that employees are familiar with. Drawing on Sutton-Smith (1997) and research mentioned in 
Spraggon and Bodolica (2018), the paradox is about balancing between organizational stability and unleashing innovative behaviours that disrupt the status quo. Spraggon and Bodolica $(2017,2014)$ also use the notion of "social ludic activities (SLAs)" to refer to the activity of playing at work.

Scott (2020) talks about "fictionalising adults' experiences of work-based learning”. With LSP application, we are talking about metaphorizing adult's experiences. Building on that, serious play in organizational development requires the acceptance of context-sensitive interpretations. In the Polish corporate culture, the paradox of intentionality is even more visible with the business culture with a high (93) uncertainty avoidance index according to Hofstede's dimensions. Furthermore, "manifestations of play as sources of creativity" (Mainemelis and Ronson, 2006) demands freedom of experimentation to bring value. By value, I mean: "positive affect tied to very specific reasons, such as involvement, surprise, uncertainty, and out-of-the-ordinary experience" (p. 91).

Having said that, to interpret "playing" in the business environments requires going beyond the ludic interpretation of the play. The closest meaning of this term is Csikszentmihalyi's (1990) flow that defines the flow experience as talking about the feeling of "floating" beyond the output or being "lost in the task". Gauntlett adds to this "participants absorbed in the Lego building process are good examples of individuals "in flow" (p. 24). Applying this approach, Gauntlett's (2007) main findings can be exposed:

(1) "Creative and visual research, methods give people the opportunity to communicate different kinds of information" (p. 182). These findings will be discussed in the strong connection to organizational communication.

(2) "Research participants need reflective time to construct knowledge" - this concept will be checked in context of self-reflection and identity exploring (p. 185)

Gauntett's findings can be supported by Hadida's (2013) concept of “cocreative settings". In other words, to create "playful experience", the individual flow should be linked to collective experience through working in a group. Hadida (2013) also emphasised the role of metaphors, imagination, story-making and micro-narrative building that help to facilitate a better understanding of core strategic business challenges.

Taking into consideration business culture in Central and Eastern Europe (CEE) region where "acceptance to play" and manifestation of emotions at work may be treated as "blocker" more than "enabler", serious play-based learning activities are still interpreted as a high-risk initiative that suspends ordinary organizational conventions. Play and joy in business are associated with emerging realities and introduction of uncontrolled phenomenon to the experience. Interestingly, Mainemelis and Ronson (2006) distinguish between "play" and "joy", while in some elements presented in the EPIC moments (especially image-taking part) are closer to experiencing joy than an intended play. This may be related to the leading interpretation of bricks like a childlike play tool, and transferring this perception to business in a tool-oriented and mechanistic way that blocks the potential of the method to be unleashed. Furthermore, "playing" is treated as a boundary spanning activity (Andersen et al., 2013) that enables various courses of actions and these moments of unexpected scenarios also bring feeling of creation and joy. Finally, what is especially significant in Polish hierarchical culture, informal play offers an alternative "to prevailing views that espouses the employee rather than the managerial perspective" (Spraggon and Bodolica, 2018, p. 846). Drawing on this perspective of dual benefits of play: "having time to play at work is a necessary condition for them to find satisfaction in their jobs, and if so, it becomes incumbent on managers to consider ways to successfully incorporate play into work in order to motivate and retain these employees" (Petelczyc et al., 2018, p. 163).
Designing
playful
employee
experience

129 
JWAM

14,1

That is why, in the process of presenting key findings, the author seeks to describe open categories adaptable to various corporate cultures-those who accept play and joy and those that are more reserved to this experience. This article also seeks for theories explaining the outcomes understood as visible, observable engagement of participants of the learning events when LSP was used. This post-factum perspective enables reflections. After the literature review linked to LSP prepared in Billund in October 2018 by the LSP Research group led by Kristen Klassen, the main conclusion is that apart from a few attempts to support practice by theory (e.g. Primus and Sonnenburg, 2018) most of research appears in a kind-of post-factum perspective.

\subsection{Theorizing "employee experience"}

In conceptualization of employee experience, the definition taken from the coaching approach is used. Experience, according to a group of researchers in introspective psychology (Włodarski, 2010), is defined as "an imprint of experienced events, situations, contacts, feelings or action in memory" (p. 75).

Creative explorations and remembering of work-related experiences. In the concept of creative explorations (2007), Gauntlett combines two elements of engaging experience:

(1) creativity through discovery and

(2) discovery thanks to self-reflection,

stating that "[c]reativity often takes place where one perspective meets another, or where the insights of one paradigm have a playful engagement with the subject-area of another" (Gauntlett, 2007, p. 23).

Analogically to experiencing flow, the self-reflection (individual experience) needs to be communicated to the group to gaining common understanding. The key element is linked to the collective intelligence transformed into collective memory and then, leads to organizational remembering. Finally, Csikszentmihalyi (2013, p. 83) describing the emergence of the problem says that "[t]here are three main sources from which problems typically arise: personal experience, requirements of the domain, and social pressures" and each of the workshop participants express the problems through the story that is linked to his/her experience which is the optimal situation to unleash creativity. This ability of creative ideation, according to Nijstad et al. (2010) is a function of dual modes of creativity: flexibility and persistence.

In LSP, the moment of sharing the stories is the place to talk about the past experience filtered by self-reflection and "adapted" to the constructed metaphors. This distortion in the way of talking about past events helps to go beyond non-declarative responses. More reflexive stories lead to more reflexive micro-narratives. Still, the focus is on the shared mental model and streaming individual experiences into a social experience to create a common platform of shared interpretations of the events. Thanks to the activity of participants "the knowledge becomes a common good" (Hofmolk, 2009, p. 9) or common-pool resources that are additionally represented in the physical form of a brick model. Moreover, as Czakon and Klimas (2014) mention, it ignites the exchanges and make intra-network communication processes even more engaging.

Furthermore, talking about time orientation, the experience is a past-oriented concept while organizational remembering is a reoccurring, ongoing process of collective memorizing. Sanfuentes and Acuña (2014) discovered that "the ignorance of the past lessens the ability to face turbulent periods, because organizations are unable to connect new alternatives with preceding experiences" (p. 289). They defined "organizational remembering" as "the essential process whereby the heterogenous character of organizational practices and traditions can be negotiated and integrated" (p. 291). These findings confirm the results of several earlier 
studies among which De Vries and Balazs (1997) is worth mentioning as the experiences refer to "coping" and "continuity" in the organizations.

Concluding the discussion on the reinforcement of remembering, Gauntlett (2007) the author who sets the context of academic papers on creative explorations and LSP application in research links the description of the "experience" to a captured "scene" that constantly reevolves in interpretations: "As the Nobel Prize-winning neuroscientist Gerald Edelman observes, we apprehend the world at each moment, as a 'unitary scene', although the scene may change continuously as we receive new stimuli or have new thoughts" (p. 17). According to Giddens (1984, p. 2), human social activities are self-reproducing-"since these structures are reproduced through the actions of individuals", recursive and continuously recreated which also constitutes approach to this research.

Finally, LSP helps to memorize the findings and remember the experience itself as it introduces social experience bringing joy of collaboration. Various research confirmed and highlighted the presence and exposure of positive emotions when generating workplace impacts (Wall et al., 2017)-it refers both to personal and organizational impact. The conceptual non-academic framework is suggested in Lego Serious Play brochure (2006, p. 4) where social bonding and constructive competition are mentioned as the elements of the workshop experience. This is also confirmed in the scientific research papers by Roos et al. (2004) and Rasmussen (2006) the theories of Piaget's Constructivism, Papert's constructionism and learning by making and building knowledge are named the background theories of this business method of facilitation. Here, the link to communication should also be mentioned to understand the concept in the context of organizational capabilities as Sutton-Smith (1997) state that "[p]lay is like language: a system of communication and expression" (p. 219) and serious play brings engaging moments to the organizational conversation. The participants build not only the LEGO models, they also shape the playful moments in their heads, together as a collective action.

Brick models as organization culture artefacts. Sanfuentes and Acuna (2014) call organizational identity "an unknown, forgotten, and confusing place" (p. 294). One of the methods to neutralize the feeling of confusion is expressing those stories through 3D LEGO brick models. During the workshops, participants transmit their individual stories in a psychologically safe environment, attaching a hypersensitive context to them.

In the LSP methods, the context is at organizational level, the closest understanding is at group level (with the other participants) and individuals create the artifacts of the culturethey build a brick model. Such meaning recreation can be summarized by Czarniawska (1992) who says that the employees reproduce the sense and artefacts of daily work and form the basis and reference points for participants' identity and ideology (Czarniawska, 1988). Oliver and Roos (2007) go even further, saying that the participants generate representations of their identities. Finally, in various articles regarding methods of organizational learning, the need to express the experiences through creation of artefacts is exposed: "[t]here is also the need to develop creative practice beyond the arts discipline, and the findings from this research include a workplace practice that supports multi-disciplinary professional artefacts" says Nottingham (2020, p. 129).

The model is seen as an important symbolic element that represents the working practice. Through story sharing a moment of reflexive and personalized learning becomes a part of shared interpretation. This is the way to construct organizational knowledge (Nolan, 2010). Additionally, this process is of iterative character which also generates engaging experience as "[t]he best learning experiences go through alternating phases of immersion and reflection" (Resnik, 2017, p. 71).

To sum up, commenting on the Polish business context, commercial reports of employee engagement show the raising role of experiential learning; however, serious play is still a niche approach in adult learning and whether applied, the perception is instrumental or
Designing playful employee experience 
JWAM

14,1

treated as a "creativity trigger". Finally, Polish researchers such as Jemielniak (2002) exposed the importance of knowing the culture through the involvement of culture participants and co-creators-in other words-through the experiences of employees.

\section{Methodological approach}

This paper is written with Durkheim' macro approach to sociology, stating that we can go beyond individual cases and should be able to discuss a broader context for social discoveries that makes findings about social existence.

This is an evaluation study of an exploratory character (Stebbins, 2001) and employs participatory observation during the training sessions. The research adopts a qualitative approach using participation observation from the position of the workshop facilitator who observes the participants to identify the character and sources of visible playful experience among participants of the developmental events.

The workshops took place between September 2018 and May 2019 in Poland in a corporate environment and discussed topics that can be clustered as organizational development, namely:

(1) Leadership

(2) Identity and company values

(3) Organizational culture

Each event was treated as a separate field experiment (exploratory fieldwork) and the moments of the most visible engagement of the participants were identified. The other event in a pair was of similar expected results, however, the main method of work was not LSP. To allow the comparison of the two workshops, a similar number of participants needed to be the same in both LSP and non-LSP workshops. The content of the workshop was ignored as the observation was focused on the employee experience and participants' reactions that illustrate the engaging moments of the workshops.

\subsection{Dual role of the facilitator and researcher-challenges and opportunities and the implications on the methodological approach}

3.1.1 Opportunities. In the participant observation "the researcher takes a role in a particular collectivity and is able to learn the functioning of the role-playing system and, especially to recognize the aspects of the role which he takes in the collectivity" (Mayntz et al., 1985, pp. 126-129). The facilitators act as "gatekeepers", acquiring knowledge from outside the community and making it accessible for members to use and engage in knowledge sharing and exchange (Yokakul and Zawdie, 2011, p. 19). In LSP method everybody is active-there is no observers in the room and there are no non-active participants. The social contract with participants covers "everybody builds, everybody shares" rule which stands for acceptance to share their experience. This is a strong starting point as the frame of the conversation is open and associated with positive climate of work.

According to Yokakul and Zawdie (2011), the role of the facilitator is to focus on knowledge management and social embeddedness, building social capital and trust and the main objective of actions to engage participants in knowledge sharing and exchange, igniting interactive learning, unleashing creativity and reacting to the dynamics within the evolving social network (Yokakul and Zawdie, 2011, p. 19-20) as "social capital facilitates knowledge flow" (p. 20). Furthermore, observational research design established by Jemielniak and Ciesielska (2018) adds to this the focus on the participants' reactions during the workshops. The facilitator should observe the dynamics of speaking and noticing visible reactionsn. An 
example of noticeable reaction can be the moments when participants: "leaned forward, spoke faster, smiled more, were more animated" (Bowden and Ciesielska, 2014 in Jemielniak, 2014, p. 20). The dynamics of conversation during LSP events is high which brings the conversation to more emotional level and makes the individual experience stronger by offering more space for personal reflections that should enable the feeling of "impact" of the participant and employee-centric workshop design which is one of the assumptions of the playful learning experience design. Thanks to creative facilitation, the level of self-reflexivity raises and reactions to personal stores are observable.

This is valid also for the facilitator as taking several roles allows to determine the meaning of a given role in a self-reflective and intersubjective way (Jemielniak, 2014) which was visible in the process of neutrality in identifying the moments with the highest number of reactions that suggest the engagement during the session and post-event self-reflection of the author when listening to recording of the workshop conversations.

3.1.2 Challenges. The duality of the role can be a challenge when analysing the scope of responsibilities during the workshop. The facilitator is responsible for providing clear instructions of how to use LEGO bricks in the case, for answering questions, providing comments on the LSP rules, correcting wrong understanding of the method, following participants stories and helping to structure them operationally.

To overcome this challenge, the impact should be put on recording the sessions to capture the stories and be able to check later if the first interpretations were the final ones. The method of research was participant observation. The precision of observation was confirmed by:

(1) taking field notes during the event

(2) taking photos of the brick models

(3) recording audio with most crucial conversations of the event

The fact of the detailed observation was linked to the demand of preparing a summary report to the client after the workshop which is in line with pracademic approach in action research, especially in creative research methods. Roos et al. (2004) represent the viewpoint that when it comes to LSP the gathered materials can be analysed to gain both academic understanding and practical value at the same time.

The data have been collected in the business environment, which makes this research full of practical conclusions and implications for managers. Furthermore, the business report prepared after each session required a rigorous way of presenting stories and themes that appeared in the conversations. The summary was based on the field notes and supported by recordings. Even when the session has not been recorded the essence of the stories has been written down on sticky notes, posters or business canvas (depending on the sessions) to confirm that the meaning behind the notes is captured from the whiteboards.

The next challenge is related to the "Bazaar Environment" (Skolik, 2014 in Jemielniak, 2014, p. 119) which suggests that with many emotional stories that sometimes are overlapping, it is impossible to create a sterile environment of conversation. The solution to that is a double verification of key insights based on the recordings and notes from the session.

\subsection{Research design}

3.2.1 Research question. The objective of this viewpoint paper is to shine a light on the generators of engagement during company workshops. To find commonalities between creative and non-creative workshop, the experience from the events that use LEGO ${ }^{\circ}$ SERIOUS PLAY ${ }^{\circledR}$ method have been compared to the workshops that use more traditional methods of learning acceleration. The research question stands as follows:

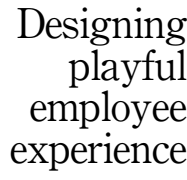

133 
JWAM

14,1

134
$R Q$. What are the elements that can engender engagement beyond the playful experience?

Still, the limitations and the question of the replicability of the research in different groups in various regions remains valid as the learning experience of the workshop participants is a highly context- and culture-sensitive issue. To neutralize this and to make sure that chosen cases are the most adequate illustrations of employees' reactions to the serious play method of work, the selection of cases was based on the clear criteria, namely type and size of the learning event, and the method of work during the learning event (see Table 1).

\section{Key findings: results and discussion}

In the first part, the EPIC conceptual framework will be introduced as the second part will cover a brief discussion around the elements of the EPIC to embed the findings into the theoretical explanation and concepts.

The EPIC framework has been constructed based on the most frequent themes that appeared during the sessions and evoked moments of engagement. The recordings from the sessions were coded thematically. The moments of the most vibrant discussions during the workshop were identified and streamed into the themes according to coding manual (Saldana, 2009).

In most of the cases the moment of engagement involved visible verbal and non-verbal responses, for example, unexpected moments of observable joy, like:

Look what I've built! (B1 workshop) or,

I didn't know that the tower can explain the story of your life (B1 workshop), or

a wave of laughing, vibrant discussion, louder voice, or the moment of meaningful silence, questions asked directly to the speakers or direct statements like "We definitely need to discuss it after the workshop" (C1 workshop) talking about the corporate values. The moments of engagement were indicated by the facilitator and then confirmed by the replay of voice recording. During A1 and A2 workshops, the table facilitators were present to indicate

\begin{tabular}{|c|c|c|c|c|c|}
\hline No. & Company & $\begin{array}{c}\text { No. of } \\
\text { participants }\end{array}$ & $\begin{array}{l}\text { Type of the } \\
\text { learning event }\end{array}$ & Method of work & $\begin{array}{c}\text { No. of } \\
\text { "engaging } \\
\text { moments" } \\
\text { identified }\end{array}$ \\
\hline $\mathrm{A} 1$ & FMCG & 80 & Mass-scale & $\begin{array}{l}\text { LEGO® SERIOUS } \\
\text { PLAY® with table } \\
\text { facilitators }\end{array}$ & 12 \\
\hline A2 & Pharmaceutical & 80 & Mass-scale & $\begin{array}{l}\text { Projective techniques } \\
\text { with table facilitators }\end{array}$ & 12 \\
\hline B1 & Classified I & 17 & $\begin{array}{l}\text { Communication } \\
\text { workshop }\end{array}$ & $\begin{array}{l}\text { LEGO® SERIOUS } \\
\text { PLAY® }\end{array}$ & 8 \\
\hline B2 & IT (BPO) & 18 & $\begin{array}{l}\text { Communication } \\
\text { workshop }\end{array}$ & Process visualization & 5 \\
\hline $\mathrm{C} 1$ & $\begin{array}{l}\text { IT (software } \\
\text { house) }\end{array}$ & 13 & $\begin{array}{l}\text { Qualitative } \\
\text { research } \\
\text { (Exploratory) }\end{array}$ & $\begin{array}{l}\text { LEGO® SERIOUS } \\
\text { PLAY® }\end{array}$ & 6 \\
\hline $\mathrm{C} 2$ & Classified II & 13 & $\begin{array}{l}\text { Qualitative } \\
\text { research } \\
\text { (Exploratory) }\end{array}$ & In-depth interviews & 4 \\
\hline
\end{tabular}

Table 1.

Overview of

selected cases 
and write down the findings from the discussion. Those two sessions were not recorded. In those cases, the identification of the engaging moments was based on the field notes of the socalled "table facilitators".

\subsection{Results: introducing the EPIC conceptual framework}

The list of elements that make the LSP event an engaging experience with the highest level of saturation is as follows (see Figure 1):

4.1.1 E-Emerging realities and relationships. "E" stands for emerging realities as during the workshops there is a sense of unexpected findings that appeared in the conversation. This "surprising outcomes" situation can be illustrated by one of the most frequently recurring comments in the first part of the workshop-"I didn't know that I need to introduce myself using this tower" (A1, B1, C1 workshops). The participants were surprised with their own reactions and interpretations. The illustration can be noticed in $\mathrm{C} 1$ workshop when two senior leaders in this company unexpectedly started conversation about their concept to create more value-based company and purpose-driven company and the rest of the participants were surprised with the level of declarations about future actions.

During the workshops, the conversations circle around the physical object, namely 3D LEGO model. Fixed formal organizational structures are replaced by spontaneous stories and emergent connections. Those relationships-the experience of co-creation and co-orientation through interactions-emerge in conversations. The LSP framework enforces nonhierarchical platform for conversation, as the managers and their opinions are equally vital to the voices of other participants. The space for actual story-sharing is by rule, distributed equally among the participants, so this is the value of contribution to the discussion that stands for the quality of conversation. In such an environment, the criteria of the final conclusions emerge as a collective contribution, without the formal ownership of the idea. Additionally, the contributors, neglecting their formal position in the hierarchy, may become "significant others" (Babbie, 2003, p. 263) or social influencers as the rules of the importance are based on the contribution instead of personal visibility or formal roles.

To explain it in the system view of life: the process of communication changes from a linear structure, where messages are sent to target audiences, to hubs of communication, where surplus audiences disturb or advance messages (Jenkins et al., 2013). What is more, socalled "complexity shocks" can also be engaging elements that created the workshop experience. Free-thinking and, therefore, playful kind of environment (Gauntlett, 2007, p. 129).

Unexpected method of expression (stories around LEGO model) and the new style of thinking (thinking through building) together with unpredictability of the reactions created kind of positive creative tension. The participants were waiting for the next task, they had to be oriented in the new method of expression and remembering and reacting to the stories of people around them. To explore more and not to lose orientation in the situation, they had to stand the tension of not being able to control the environment.

\begin{tabular}{|l|l|}
\hline & Thematic coding \\
\hline $\mathbf{E}$ & Emerging realities / emergent situations / unexpected discoveries \\
\hline $\mathbf{P}$ & Playful atmosphere \\
\hline $\mathbf{I}$ & $\begin{array}{l}\text { Images of physical models (capturing the scenes by taking photos, 'snapshot-like' } \\
\text { environment) }\end{array}$ \\
\hline $\mathbf{C}$ & Creation or Co-Creation as a collective experience \\
\hline $\mathbf{( S )}$ & Stories (narratives) \\
\hline
\end{tabular}

\section{Designing playful employee experience}


JWAM

14,1
As the reality is uncontrollable and the individual interpretation creates the shared vision and understanding, the ideas developed in this way can be promoted much easier among stakeholders. The sensing of immediate influence (Knudsen and Lemmergaard, 2014) is also a source of engagement. Fairhurst and Putnam (2004) explained this experience as being in an ongoing state of forming as participants take part in the formative activity.

4.1.2 P-Playful participation through contribution. Participation was obligatory as it was mentioned as a pillar of a social contract during the workshops. There is a rule that "everybody builds and everybody shares" their stories. This enabled the space of $100 \%$ contribution to the discussion. Additionally, the method itself encourages to take part in these experience in a playful way. The tool-LEGO bricks introduce the climate of a playful activity.

The observation from the B1 workshop suggests that the engagement was driven by the fact that the participants generated ideas to real business problems. Out of the playful experience, serious business discussions emerged. For example, starting with rather instrumental questions, the participants discovered the impactful pain points linked to the corporate culture.

One of the participants mentioned that even a "standing position" during the workshop was making the whole atmosphere less formal.

4.1.3 I-Image that sticks in your head and. . you can share it. During all the sessions in LSP methods, most of the participants were taking the photos of the model. The engagement grows with the instant comments from Facebook friends asking about "What are you doing at work?" (happened during $\mathrm{A} 1, \mathrm{~B} 1$ and $\mathrm{C} 1$ session). The experience of being a creative creature leaves an imprint enough to take and share the photo and then spread a word.

The images generated during the workshops had triple functions:

(1) Reason-to-Talk - The participants generated an interesting content to post.

(2) Reason-to-Believe - The participants could use the name of the method to "label their experience". Especially in the up to 20 participant workshops, participants ask about the detailed name of the method.

Reason-to-Share - Instant discussion in social media about the session impacted the level of engagement of many participants in a positive way. These findings can also be confirmed by the number of photos on LinkedIn or Instagram with \#legoseriousplay hashtag.

4.1.4 C-Creation as a collective experience. This finding is based on two types of observation: the longer the workshop, the more opportunities to experience the collective exercises (for example, building a shared model) and more moments of discoveries for participants, especially in A1 workshop were easy to notice as the discussions went faster and louder.

The workshop may change the perception of the social reality as typically, people do not play at work, so the participants observe others in a totally new more playful business reality. This playful space creates a perception of "total social immersion" and the value of the individual is based on the contribution, especially when the facilitator applies a "Shared Model" technique. The differentiation between "play" and "serious play" is ownership and the control over the structure is in the hands of the facilitator not the primary stakeholders.

The last element did not receive the level of saturation equal to the previous ones, although it is worth mentioning as it embraces: creativity, image creation and shared identity.

According to Gauntlett, "the stories we tell about ourselves are crucially important to identity" (Gauntlett, 2007, p. 89) and we needed to adopt the ability to create narratives about ourselves as "the most important stories are those we talk about ourselves" (Gauntlett, 2007, p. 90).

The LSP workshop opens space for sharing individual micro-stories as during the short workshop (up to 2:30 h) each participant speaks at least four times. The meaning-creation requires everyone's contribution to the conversation. 
Micro-narratives as a form of communication are closely linked to the expression of identity or verbal conceptualization of values:

It would be quite impossible for human beings to codify and to put in order such a complex and chaotic experience as reality. In this sense, the art of storytelling [...] should be considered like a key tool for identity building, either individual or collective. At the same time, it should be seen as a way for organizing and sharing collective knowledge and personal experiences (Venditti et al., 2017, pp. 273-274). With remote workshops, the stories shared by the participants have even more potential to boost engagement as there is no physical space shared, and people fill the social space with their stories.

\subsection{Discussion: explaining results in relations to theories and concepts}

In this part, each element of the EPIC(s) model will be briefly explained through a lens of theoretical concepts.

4.2.1 E-Emerging realities and relationships. The concept of emerging strategies has been developed by Henry Mintzberg (1987, 1994). In the LSP method, emergent realities and systems view of life play an important role. This is close to Coreen's CCO (communication constitutes organization) principle that sees communication as organizing and states that:

Organization emerges in the interplay of the textual world of ideas and interpretations and the practical world of an object-oriented conversation. (Cooren et al., 2006, p. xi)

The significance of the emergent character of events in LSP was also mentioned by other facilitators of the method. They observed and studied phenomena grouped under the term "emergence," which management theorist Jeffrey Goldstein calls "the arising of novel and coherent structures, patterns, and properties, during the process of self-organization in complex systems" (Eberle, 2014, p. 220). Having said that, the conversation that happens around the table with the bricks fits to the definition of "strategic serendipity" (Knudsen and Lemmergaard, 2014) as it creates unexpected communicative opportunities.

In this vision of communication as a set of planned activities, the conversation needs to be framed in a deliberate way that leads to tangible outputs and "attributes success to rational planning" (Knudsen and Lemmergaard, 2014, p. 392). In the emergent communication, the reality can be controlled only to a certain extent (Pfeffer and Salancik, 1978). It is still purposeful and intentional, however, not planned.

According to Mintzberg (2017), the first step in building organizational engagement is "to establish a sense of urgency" (para. 5). The urgent challenges are expressed verbally by the workshop participants when sharing their stories. In this rather chaotic communicative bazaar environment some structures that can frame conversation around organizational changes may emerge (Mintzberg, 2017), creating communicative opportunities. The urgency is enhanced by the personal involvement of employees.

4.2.2 P-Playful participation through contribution.

Play makes us more interesting and better adjusted in social circumstances; it is education for the public self. (Eberle, 2014, p. 217)

The participatory character of the workshop helps getting orientation and understanding of the situation and in the next step contributes through insightful stories. According to crosscultural development strategy model elaborated by Wujec (2010), communication, together with an approach and modus operandi are the elements of "[e]laboration of strategy". She claims that identification of the situation and mutual cultural education in order to know and accept national or organizational culture is not sufficient to reach the level of a thorough understanding of a problem as "facilitated collaboration" is needed to achieve effective results. In this definition, "effectiveness" stands for the quality of collectively elaborated solutions. 
JWAM

14,1

138

According to the typology of participation presented by Tufte and Mefalopulos (2009), "participation by collaboration" type of social presence is the dynamics that emerges during LSP workshops. Personal impact and contribution directs the climate into "Participatory Communication" as a leading communicative framework (pp. 6-7). Drawing on participants' reaction, the author situates the type of participation as active, horizontal and multifaceted participation.

Furthermore, not to interpret findings only through the lenses of coaching, according to modern interpretations of social constructionism in Resnick's (2017) concept of Lifelong Kindergarten the building blocks of an engaging experience are:

(1) Projects

(2) Passion

(3) Peers

(4) Play

Discussing the participation scheme during the LSP events "Peers" and "Projects" and "Play" are usually incorporated into the workshop design while "Passion" evokes in the conversation. This was visible especially in A1 workshop as the participants were discussing the recent project in the organization and just enabling them a space to talk about project-related issues with their peers was enough to ignite the engagement.

4.2.3 I-Image that sticks in your head and. . you can share it.

Image-driven communication-Sharing workshop experience through images.

During the workshop the abstract concepts transform into the models and then, into stories.

In the modernistic tradition, persuasion and image management are the essence of strategic communication (Hallahan et al., 2007). In this image-capturable reality the sense is created by:

(1) reflecting ideas through physical models (visualizing the abstract concept)

(2) the feeling of creating a physical thing and

(3) creating a physical evidence of the discussion

Those elements help creating memories that are easy-to-be-captured artifacts of participants' experience.

Furthermore, likeability together with shareability level of these "experiential snapshots" is high. According to Rzycka's model of methods of recruiting clients for internal coaching (Rzycka, 2010, p. 187), one of the most effective method is word of mouth marketing understood as an employee-to-employee recommendation through talking about their experience and effects of the training. In the case of LSP, the difficulties in disseminating information were neutralized by bottom up spreading information through the photos of LEGO models.

The images generated during the workshops had triple functions:

(1) Reason-to-Talk - The participants generated an interesting content to post.

(2) Reason-to-Believe - The participants could use the name of the method to "label their experience". Especially in the up to 20 participant workshops, participants ask about the detailed name of the method.

(3) Reason-to-Share - Instant discussion in social media about the session impacted the level of engagement of many participants in a positive way. 
The experience of being a creative creature leaves an imprint enough to take and share the photo and then spread a word.

4.2.4 C-Creation as a collective experience.

Creative activity seems to give people a special buzz. (Gauntlett, 2007, p. 25)
Designing playful employee experience

Self-exploration that leads to creative discovery in a social space. This creative constructive tension is needed as [t]he goal of social constructivism is to identify how individuals and groups of people understand their co-created perceptions of social reality (Denzin and Lincoln, 2005), which is fluid and constantly changing through the interactions, refers to the notion of "contribution" than "co-creation" or "co-creativity". Andersen and Kragh (2010) claims that creation of shared identity is a necessity to stay competitive in current fast-paced environment. He mentions the need to generate "creative" inputs and be developed as the boundary spanning. In most of the workshops, the creative discoveries generated needs for further discussion.

When creative discovery does not take place, Allegre (2013) links the experience of creative confidence to the reframing of the situation as strategic thinking and creativity both entail the reframing of an organization's challenges and the generation of new ideas through the combination, adaptation or improvement of existing, ideas, processes or products (p. 4)

Furthermore, apart from the concept of creative discovery, co-creation is mentioned by many researchers as a source of engagement (Dann, 2018).

Finally, the "daily" creativity is important to be discussed. Gauntlett (2007, p. 19) claims that "creativity is much more commonplace" and "may include everyday ideas, writing, making, management, self-presentation and even creative speech and thought". The inevitable observation is that the presence of bricks generates curiosity and [c]uriosity, a form of anticipation, leads to discovery, a dividend of play (Eberle, 2014, p. 223).

\section{Future perspectives}

Communication is emerging as a framework of conversation that encourages to self-reflection and the rules imposed create expectations of contribution to the shared vision. The feeling of creation accelerates the conversation as manoeuvring through the stories and metaphors helps reaching unconscious statement that goes beyond the declarative level, enabling the design of "organizational stories".

\subsection{Research limitations}

First, the main limitation of this research is related to the participant observation method only and the workshops findings are related to one country only. The further investigation should involve application of the methods that are more advanced technologically, for example emotion recognition software to be able to support the findings from participatory observation with quantitative or generally more tangible evidence linked to the learning outcomes.

Second, through the observation, without searching for the deeper insights, it is not possible to clarify the blurred lines between the engagement generated as a result of satisfaction on a surface layer-the brick building experience that is demanded by the context (Botte et al., 2016) and the engagement that is a part of the learning experience generated through social experience and self-reflection.

Third, the sample is not sufficient to generalize, especially when we are talking about such context- and culture-sensitive research, however, the research is replicable and the EPICs framework may be used as a direction to verify the insights. Having said this, EPIC model 
JWAM

14,1

contains the categories that are wide enough to be contextually adapted to various organizational and cultural contextual settings, however, it cannot be treated as a final model proposal.

\subsection{Practical implications in the age of AI and global pandemic}

The EPIC framework gives directions and covers categories wide open to experimenting in different contextual settings. It offers a flexible concept that by reflexive human resources manager can be incorporated in various areas, not promising clear cuts between the climate and concrete business solutions, however in most of the cases bringing the positivity to the organization.

Second, the sources of engagement that have been identified in the pre-pandemic organizational context can be helpful in designing a digital working environment.

5.2.1 "Emerging strategy", strategizing and future scenario thinking in the times of pandemic. This paper contributes to the discussion about employee engagement. The importance of the "emergent realities" as a source of joy and engagement was confirmed. Rasmussen (2006) stated that LSP is a process tool that prepares teams emotionally to embrace change. Earlier it was one of the main findings taken from Roos et al. (2004) research that focused on the strategy. This viewpoint recurred with the practitioners' research (Geithner and Menzel, 2016) confirms that even the activity of mapping of a complex situation may be a source of engagement:

By having a complete picture of the current system, including team roles, relationships, and culture, and by testing the system with specific scenarios, team members gain more confidence, insight, and commitment in dealing with future events (Geithner and Menzel, 2016, p. 229).

Apart from the playing emergence, the engagement is created when people are allowed to experiment and play with authentic scenario based on real situations and strategies that activate trial-and-error learning in a creative way that is one of the elements of engaging learning experience.

Finally, creativity is one of the future work skills announced by World Economic Forum (2020). As humans, we need to "do our creative homework" first to be able to get to the imaginative task after to rewire business. And here we have a recommendation:

What revolutionises human play is imagination. Francis Steen in one of his speeches at the University of California

Table 2.

Explanation of EPIC model in the context of digital environment

\begin{tabular}{|c|c|c|}
\hline & Traditional space & Digital workspace \\
\hline $\mathrm{E}$ & $\begin{array}{l}\text { Emerging realities/emergent situations/ } \\
\text { unexpected discoveries }\end{array}$ & $\begin{array}{l}\text { Content of stories shared by employees does not } \\
\text { change. The insights are equally impactful }\end{array}$ \\
\hline $\mathrm{P}$ & Playful atmosphere & $\begin{array}{l}\text { Creative workshops with real bricks delivered before } \\
\text { the workshop }\end{array}$ \\
\hline $\mathrm{I}$ & $\begin{array}{l}\text { Images of physical models (capturing the } \\
\text { scenes by taking photos, "snapshot-like" } \\
\text { environment) }\end{array}$ & $\begin{array}{l}\text { Pictures are easy to be taken. Now, with employee } \\
\text { advocacy and "instagramization" or culture trends, the } \\
\text { shareability of the materials should be even higher }\end{array}$ \\
\hline $\mathrm{C}$ & $\begin{array}{l}\text { Creation or Co-Creation as a collective } \\
\text { experience }\end{array}$ & $\begin{array}{l}\text { Combining realities: Real bricks available at home of } \\
\text { an employee and digital interactions }\end{array}$ \\
\hline (S) & Stories (narratives) & $\begin{array}{l}\text { The content of the stories can be limited by the home } \\
\text { environment, so the proposed solution is to put more } \\
\text { attention into describing a brief summary of your story } \\
\text { on the sticky notes, using spaces as whiteboards }\end{array}$ \\
\hline
\end{tabular}


Talking about benefits of creativity, we should take into consideration the need of persistence as Scott (2020, p. 123) claims: "Persistence is required when attempting creativity in the workplace" challenging the organizational capabilities with spaces for collaboration, critical reflection and exploration with "revisiting, reviewing and revising" as a leading approach. Before we start to re-imagine organizational realities in a mindful and impactful way while designing DEX, we need to learn the rules of playing and strategizing with patience and persistence.

\section{References}

Abramis, D.J. (1990), "Play in work: childish hedonism or adult enthusiasm?", American Behavioral Scientist, Vol. 33, pp. 353-373.

Andersen, P.H. and Kragh, H. (2010), "Sense and sensibility: two approaches for using existing theory in theory-building qualitative research", Industrial Marketing Management, Vol. 39 No. 1, pp. 49-55.

Andersen, P.H., Kragh, H. and Lettl, C. (2013), "Spanning organizational boundaries to manage creative processes: the case of the LEGO Group", Industrial Marketing Management, Vol. 42 No. 1, pp. 125-134.

Andersen, N.A. (2009), Power at Play: The Relationships between Play, Work, and Governance, Palgrave Macmillan, Basingstoke.

Ashton, D. and Giddings, S. (2018), "At work in the toybox: bedrooms, playgrounds and ideas of play in creative cultural work", The International Journal of Entrepreneurship and Innovation, Vol. 19 No. 2, pp. 81-89.

Babbie, E. (2003), Badania Spoteczne w Praktyce, PWN, Warsaw.

Bonneau, C., Bourdeau, S. and Sergi, V. (2017), "Up to what point can work dissolve in a serious game? A participant perspective on the Lego Serious Play method", presented at the 33rd EGOS Colloquium, Copenhagen, July 6-8, 2017, Sub-theme 39: The Games Organizations Play: The Uses and Effects of Play at Work.

Botte, B., Imbellone, A., Marinensi, G. and Medaglia, C.M. (2016), "The ludic and narrative components in game based learning: a classroom training experience", Proceedings of the European Conference on Information Management and Evaluation, Vol. 01, pp. 82-88, 2016.

Bowden, A. and Ciesielska, M. (2014), "Accretion, angst and antidote: the transition from knowledge worker to manager in the UK heritage sector in an era of austerity", in Dariusz, J. (Ed.), 2014, the Laws of the Knowledge Workplace. Changing Roles and the Meaning of Work in KnowledgeIntensive Environments, Gower Publishing, pp. 11-24.

Cooren, F., Taylor, J.R. and Van Every, E.J. (Eds), (2006), Communication as Organizing: Empirical and Theoretical Explorations in the Dynamic of Text and Conversation, Lawrence Erlbaum Associates, Mahwah, NJ.

Csikszentmihalyi, M. (1990), Flow: The Classic Work on How to Achieve Happiness, Rider, London.

Csikszentmihalyi, M. (2013), Creativity: Flow and the Psychology of Discovery and Invention/Mihaly Csikszentmihalyi, HarperCollins Publishers, New York [etc.].

Czakon, W. and Klimas, P. (2014), "Innovative networks in knowledge-intensive industries: how to make them work? An empirical investigation into the Polish Aviaton Velley", in Jemielniak, D. (Ed.), The Laws of the Knowledge Workplace. Changing Roles and the Meaning of Work in Knowledge-Intensive Environments, Gower Publishing, pp. 133-159.

Czarniawska, B. (1992), Exploring Complex Organizations: A Cultural Perspective, Barbara Czerniawska-Joerges, Sage, Newbury Park.

Czarniawska, B. (1998), A Narrative Approach to Organization Studies, SAGE, London.
Designing playful employee experience 
JWAM

14,1

Dann, S. (2018), "Facilitating co-creation experience in the classroom with Lego serious play", Australasian Marketing Journal, Available online 8 June 2018.

De Vries, M.F.R.K. and Balazs, K. (1997), "The downside of downsizing”, Human Relations, Vol. 50 No. 1, p. 11.

Denzin, N.K. and Lincoln, Y.S. (2005), "Introduction: the discipline and practice of qualitative research", in The Sage Handbook of Qualitative Research, Sage Publications, Thousand Oaks, CA, pp. 1-32.

Eberle, S.G. (2014), "The elements of play toward a philosophy and a definition of play", American Journal of Play, Winter 2014, pp. 214-233.

Eghenter, A.S. (2018), "Organizational creativity, play and entrepreneurship”, Organization Studies, Vol. 39 Nos 2/3, pp. 169-190.

Executive Discovery LLC. report (2002), The Science of LEGO ${ }^{\circledR}$ SERIOUS PLAY ${ }^{\mathrm{TM}}$, Play. Construction. Imagination, report, available at: https:/thinkjarcollective.com/wp-content/ uploads/2014/09/the-science-of-lego-serious-play.pdf (accessed 5 July 2021).

Fairhurst, G.T. and Putnam, L. (2004), "Organizations as discursive constructions", Communication Theory, Vol. 14 No. 1, pp. 5-26.

Gauntlett, D. (2007), Creative Explorations: New Approaches to Identities and Audiences, Taylor \& Francis, London.

Geithner, S. and Menzel, D. (2016), "Effectiveness of learning through experience and reflection in a project management simulation”, Simulation and Gaming, Vol. 47 No. 2, pp. 228-256.

Giddens, A. (1984), The Constitution of Society, Polity, Cambridge.

Hadida, A.L. (2013), "Let your hands do the thinking!", Strategic Direction, Vol. 29 No. 2, pp. 3-5.

Hallahan, K., Holtzhausen, D., Ruler van, B., Vercic, D. and Sriramesh, K. (2007), "Defining strategic communication", International Journal of Strategic Communication, Vol. 1 No. 1, pp. 3-35.

Heyler, R. (2015), "Learning through reflection: the critical role of reflection in work-based learning (WBL)", Journal of Work-Applied Management, Vol. 7 No. 1, pp. 15-27.

Hinthorne, L.L. and Schneider, K. (2012), "Playing with purpose: using serious play to enhance participatory development communication in research", International Journal of Communication, Vol. 6, pp. 2801-2824.

Hofstede Insight, available at: https:/www.hofstede-insights.com/country/poland/ (accessed 03 April 2021).

Holmes, B. and Douglas, K. (2012), "Human nature: being playful”, New Scientist, Vol. 214 No. 2861, pp. 38-40, available at: https:/www.newscientist.com/article/mg21428610-300-human-naturebeing-playful/\#ixzz6r1ElzlZs.

Holmolk, J. (2009), Internet Jako Nowe Dobro Wspólne, (translation: Internet as a common good), Wydawnictwa Akademickie i Profesjonalne, Warszawa.

Huizinga, J. (1995), Homo Ludens: A Study of the Play-Element in Culture, Taylor \& Francis, London.

Inamizu, N. and Makishima, M. (2018), "Job performance explains work engagement: curvilinear relations between the two", Annals of Business Administrative Science, Vol. 17, pp. 159-169.

Jemielniak, D. and Ciesielska, M. (Eds) (2018), Qualitative Methodologies in Organization Studies Volume II: Methods and Possibilities, Palgrave Macmillan, Cham.

Jemielniak, D. (2002), "Kultura: odkrywana czy konstruowana?”, (translation: “Culture of discovering or exploring?”), Master of Business Administration, Vol. 2 No. 55, pp. 28-30.

Jemielniak, D. (Ed.) (2014), The Laws of the Knowledge Workplace. Changing Roles and the Meaning of Work in Knowledge-Intensive Environments, Gower Publishing.

Jenkins, H., Ford, S. and Green, J. (2013), Spreadable Media: Creating Value and Meaning in a Networked Culture, New York University Press, New York. 
Kark, R. (2011), "Games managers play: play as a form of leadership development", Academy of Management Learning and Education, Vol. 10 No. 3, pp. 507-552.

Knudsen, H. and Lemmergaard, J. (2014), "Strategic serendipity: how one organization planned for and took advantage of unexpected communicative opportunities", Culture and Organization, Vol. 20 No. 5, pp. 392-409.

LEGO SERIOUS PLAY brochure (2006), available at: https://www.rasmussenconsulting.dk/ downloads-and-links (accessed 03 April 2021).

Liu, A. (2019), "Making joy a priority at work", Harvard Business Review Digital Articles, pp. 2-7.

Mainemelis, C. and Ronson, S. (2006), "Ideas are born in fields of play: towards a theory of play and creativity in organisational settings", Research in Organizational Behavior, Vol. 27, pp. 81-131.

Mayntz, R., Holm, K. and Hübner, P. (1985), Wprowadzenie Do Metod Socjologii Empirycznej, PWN, Warsaw.

Mintzberg, H. (1987), "The strategy concept I: five Ps for strategy", California Management Review, Vol. 30 No. 1, pp. 11-24.

Mintzberg, H. (1994), The Rise and Fall of Strategic Planning: Reconceiving the Roles for Planning, Free Press, Plans.

Mintzberg, H. (2017), "Transformation from the top? How about engagement on the ground?", available at: http://www.mintzberg.org/blog/transformation-from-the-top-how-aboutengagement-on-the-ground (accessed 20 June 2019).

Nijstad, B.A., De Dreu, C.K.W., Rietzschel, E.F. and Baas, M. (2010), "The dual pathway to creativity model: creative ideation as a function of flexibility and persistence", European Review of Social Psychology, Vol. 21 No. 1, pp. 34-77.

Nolan, S. (2010), "Physical metaphorical modelling with LEGO as a technology for collaborative personalised learning", Technology-Supported Environments for Personalized Learning: Methods and Case Studies, IGI Global, pp. 364-385.

Nottingham, P.M. (2020), "Professional artefacts: evaluating creative outcomes for work-based inquiry”, Journal of Work-Applied Management, Vol. 12 No. 2, pp. 127-139.

Oliver, D. and Roos, J. (2007), "Beyond text: constructing organizational identity multimodally", British Journal of Management, Vol. 18, pp. 342-358.

Petelczyc, C.A., Capezio, A., Wang, L., Restubog, S.L.D. and Aquino, K. (2018), "Play at work: an integrative review and agenda for future research", Journal of Management, Vol. 44 No. 1, pp. 161-190.

Pfeffer, J. and Salancik, G. (1978), The External Control of Organizations A Resource Dependence Perspective, Harper \& Row, New York.

Primus, D.J. and Sonnenburg, S. (2018), "Flow experience in design thinking and practical synergies with Lego serious play", Creativity Research Journal, Vol. 30 No. 1, pp. 104-112.

Rasmussen, R. (2006), "When you build in the world, you build in your mind", Design Management Review 2006; Summer, 2006, Vol. 17 No. 3, 80, pp. 56-63.

Resnick, M. (2017), Lifelong Kindergarten. Cultivating Creativity through Projects, Passion, Peer, and Play, The MIT Press, Cambridge, Massachusetts.

Roos, J., Victor, B. and Statler, M. (2004), "Playing seriously with strategy”, Long Range Plann, Vol. 37 No. 6, pp. 549-568.

Rzycka, O. (2010), "Manager, coaching, coaching-based management - coach's insights (subjective approach)", in Czarkowska Lidia, D. (Ed.), Coaching as a Method of Developing Human Potential, Academic and Professional Press by Kozminski University, Warsaw, pp. 176-182.

Saldana, J. (2009), The Coding Manual for Qualitative Researchers, Sage Publications, Los Angeles, CA.

Sanfuentes, M. and Acuña, E. (2014), “The castaways of life': a study of organizational remembering within the context of a Chilean Geriatric Hospital", Culture and Organization, Taylor \& Francis Group, Vol. 20 No. 4, pp. 288-306. 
JWAM

14,1

Schrage, M. (2000), Serious Play: How the World's Best Companies Simulate to Innovate, Harvard Business School Press, Boston, MA.

Scott, D. (2020), "Creatively expanding research from work-based learning”, Journal of Work-Applied Management, Vol. 12 No. 2, pp. 115-125.

Skolik, S. (2014), "Qualitative research on the organization of work in internet prosumer projects", in Jemielniak, D. (Ed.), The Laws of the Knowledge Workplace. Changing Roles and the Meaning of Work in Knowledge-Intensive Environments, Gower Publishing, pp. 113-132.

Spraggon, M. and Bodolica, V. (2014), "Social ludic activities: a polymorphous form of organizational play”, Journal of Managerial Psychology, Vol. 29 No. 5, pp. 524-540.

Spraggon, M. and Bodolica, V. (2017), "Collective tacit knowledge generation through play: integrating socially distributed cognition and transactive memory systems", Management Decision, Vol. 55 No. 1, pp. 119-135.

Spraggon, M. and Bodolica, V. (2018), "A practice-based framework for understanding (informal) play as practice phenomena in organisations", Journal of Management and Organization, Vol. 24 No. 6, pp. 846-869.

Statler, M., Heracleous, L. and Jacobs, C. (2011), "Serious play as a practice of paradox", Journal of Applied Behavioral Science, Vol. 47 No. 2, pp. 236-56.

Stebbins, R.A. (2001), Exploratory Research in the Social Sciences, SAGE, Thousand Oaks, CA, London. Sutton-Smith, B. (1997), The Ambiguity of Play, Harvard University Press, Cambridge, MA; London.

Tufte, T. and Mefalopulos, P. (2009), Participatory Communication: A Practical Guide, World Bank Publications, The World Bank, Washington, DC, No. 5940.

Venditti, S., Piredda, F. and Mattana, W. (2017), "Micronarratives as the form of contemporary communication”, The Design Journal, Vol. 20, pp. 273-S282.

Wall, T., Russell, J. and Moore, N. (2017), "Positive emotion in workplace impact: the case of a workbased learning project utilising appreciative inquiry", Journal of Work-Applied Management, Vol. 9 No. 2, pp. 129-146.

Wheeler, S., Passmore, J. and Gold, R. (2020), "All to play for: LEGO® SERIOUS PLAY® and its impact on team cohesion, collaboration and psychological safety in organisational settings using a coaching approach", Journal of Work-Applied Management, Vol. 12 No. 2, pp. 141-157.

Włodarski, W. (2010), “Admit' model - management and influence domain”, in Czarkowska Lidia, D. (Ed.), Coaching as a Method of Developing Human Potential, Academic and Professional Press by Kozminski University, Warsaw, pp. 64-81.

World Economic Forum (2020), available at: https://www.weforum.org/agenda/2020/10/top-10-workskills-of-tomorrow-how-long-it-takes-to-learn-them/ (accessed 03 April 2021).

Wujec, B. (2010), "Cross-cultural coaching”, in Czarkowska Lidia, D. (Ed.), 2010, Coaching as a Method of Developing Human Potential, Academic and Professional Press by Kozminski University, Warsaw, pp. 162-175.

Yokakul, N. and Zawdie, G. (2011), "The knowledge sphere, social capital and growth of indigenous knowledge-based SMEs in the Thai dessert industry", Science and Public Policy (SPP), Vol. 38 No. 1, pp. 19-29.

\section{Corresponding author}

Monika Sońta can be contacted at: msonta@kozminski.edu.pl

For instructions on how to order reprints of this article, please visit our website:

www.emeraldgrouppublishing.com/licensing/reprints.htm

Or contact us for further details: permissions@emeraldinsight.com 